\title{
Systemic sarcoidosis with caseating granuloma
}

\author{
Fariba Binesh, ${ }^{1}$ Hassan Halvani, ${ }^{2}$ Hossein Navabii ${ }^{3}$ \\ 1Pathology Department, Shahid Sadoghi University, Yazd, Islamic Republic of Iran; \\ ${ }^{2}$ Internal Medicine Department, Shahid Sadoghi University, Yazd, Islamic Republic of Iran; \\ ${ }^{3}$ Shahid Sadoghi Hospital, Yazd, Islamic Republic of Iran
}

Correspondence toDr Fariba Binesh, binesh44@yahoo.com

\section{Summary}

Sarcoidosis is a multi-systemic disease, the diagnosis of which depends on the presence of non-necrotising granulomas in a biopsy specimen. However, variants such as necrotising sarcoid granuloma make it difficult to differentiate the disease from other infectious processes, especially tuberculosis. Here the authors describe the case of a 58-year-old Iranian woman who developed granulomas with extensive necrosis in a systemic sarcoidosis that affected the lung, liver and spleen. These findings led to a diagnosis of tuberculosis and delayed appropriate treatment.

\section{BACKGROUND}

Sarcoidosis is a disease of unknown aetiology where noncaseating granulomas form in one or more organs and tissues. The lung and lymphatic systems are most frequently involved, but sarcoidosis may affect any organ. Necrotising sarcoid granuloma (NSG) is an uncommon condition that primarily involves the lung. It is estimated that between $1.6 \%$ and $4 \%$ of pulmonary sarcoidosis cases present as NSG, which is generally limited to the lung with extrapulmonary involvement being very rare. ${ }^{1}$

The characteristic pathological features of NSG are confluent granulomas, granulomatous angitis and necrosis within granulomas, varying from tiny foci to large foci of infarct-like necrosis. Granulomatous infection, especially tuberculosis, should be excluded before making a diagnosis of NSG. We describe one of the very few reported cases of NSG with pulmonary and extra-pulmonary involvement.

\section{CASE PRESENTATION}

A 58-year-old Iranian female was referred to the outpatient clinic with a 5-month history of worsening non-productive cough, night sweats, low-grade fever and a 6-kg weight loss. Her medical history revealed diabetes mellitus, which was controlled with glybenclamid. There was no family history of lung disease. The patient was a housewife, who did not smoke and did not have a household pet. On physical examination, she appeared in relatively good physical condition, with mild fever $\left(38^{\circ} \mathrm{C}\right)$ but no abnormal clinical symptoms. Blood pressure was 140/85 mm Hg. A normal breathing rhythm was observed. Abdominal examination showed mild hepatosplenomegaly. The extremities did not reveal cyanosis or clubbing and there were no skin lesions. Neurological examination was also normal.

\section{INVESTIGATIONS}

Laboratory findings showed serum glutamic oxaloacetic transaminase $85 \mathrm{mg} / \mathrm{dl}$, serum glutamate pyruvate transaminase $90 \mathrm{mg} / \mathrm{dl}$, alkaline phosphatase 500, and erythrocyte sedimentation rate $85 \mathrm{~mm} / \mathrm{h}$. White blood cell count was $6.4 \times 10^{9} / 1$, haemoglobin $10 \mathrm{mmol} / 1$ and platelet count
$300 \times 10^{9} / 1$. Eosinophilia was not found. Serum calcium was 10 and ACE concentration was normal. Serum protein electrophoresis was within normal limits. Antineutrophil cytoplasmic antibodies (ANCA) and anti-DNA antibodies were not detected. Chest radiography and thorax CT scan showed diffuse bilateral pulmonary nodules, especially around bronchovascular bundles, and small mediastinal lymphadenopathies (figure 1). Pulmonary function tests showed a mild restrictive pattern. Abdominal sonography revealed mild hepatosplenomegaly. A purified protein derivative test was negative. Fibrotic bronchoscopy with bronchoalveolar lavage (BAL) and a transbronchial lung biopsy showed no endobronchial abnormality. Acid fast bacilli were not found in the BAL fluid but a specimen was sent for mycobacterial culture. Histopathological analysis of the biopsies revealed only mild chronic non-specific inflammation. The patient then underwent liver biopsy. Histopathological evaluation of the liver specimen showed liver tissue with chronic granulomatous inflammation containing multi-nuclear giant cells of the Langerhans and foreign body type. No acid fast

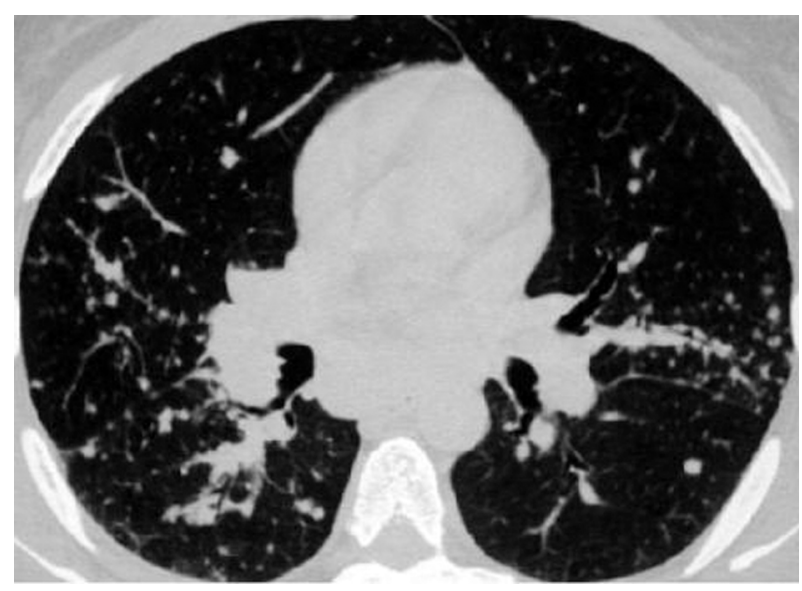

Figure 1 Thorax CT scan showing diffuse bilateral pulmonary nodules especially around bronchovascular bundles and small mediastinal lymphadenopathies. 


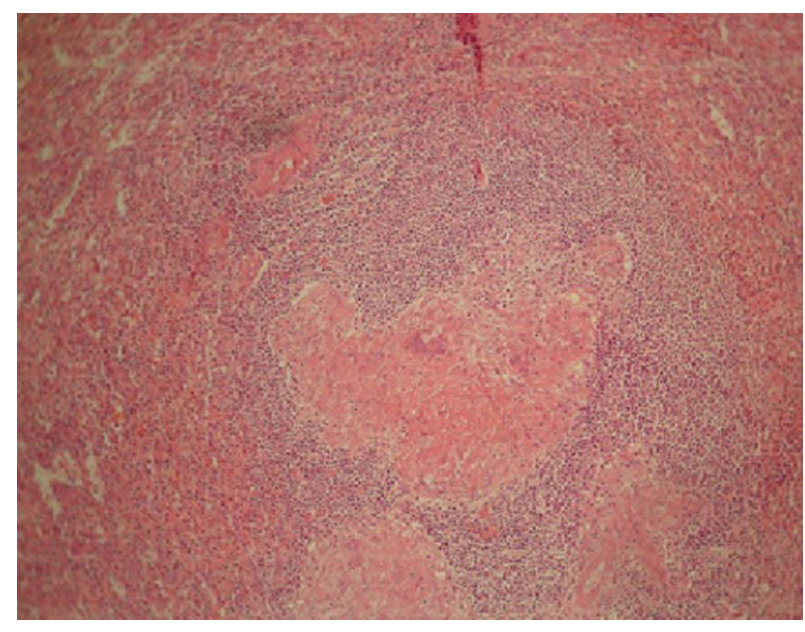

Figure 2 Section showing splenic tissue with multiple caseating granulomas.

bacilli or necrosis were observed. At this point, the differential diagnosis included tuberculosis, sarcoidosis or other granulomatous diseases and Hodgkin's lymphoma. The result of the mycobacterial culture was negative and as the patient had a normal ACE level, splenectomy was carried out in order to obtain a definite diagnosis and especially to rule out Hodgkin's lymphoma. On gross examination, small and large series of confluent whitish nodules extensively replacing the splenic parenchyma were observed. Routinely processed sections revealed splenic tissue heavily affected with multiple granulomas. Large multi-nucleated giant cells were distributed in the immediate vicinity of these granulomatous areas. There was extensive central necrosis, which was infarct-like and in some areas looked caseous (figure 2). In view of the clinicoradiological features, the patient's ethnic background and the presence of chronic necrotising granulomatous inflammation in the splenectomy material, a diagnosis of tuberculosis was made.

\section{DIFFERENTIAL DIAGNOSIS}

Granuloma formation is a non-specific immunological response, which can be triggered by a wide range of infections, chemicals, enzyme defects, neoplasms, allergens and other conditions.

\section{TREATMENT}

The patient was treated with $300 \mathrm{mg}$ isoniazide, $600 \mathrm{mg}$ rifampicin, $1500 \mathrm{mg}$ pyrazinamide and $800 \mathrm{mg}$ ethambutol daily for 6 months. During this period the patient was carefully followed, but as no significant changes were observed, mycobacterial infection was ruled out. After the patient's history, chest x-ray, liver and spleen specimens were reviewed, the diagnosis was changed to sarcoidosis with extensive necrosis. The patient was treated with prednisone $30 \mathrm{mg} /$ day for 6 weeks, and a remarkable improvement in clinical and laboratory status was achieved. The rapid clinical response led to the final diagnosis of NSG.

\section{OUTCOME AND FOLLOW-UP}

After 1-year follow-up the patient is in good condition, her erythrocyte sedimentation rate is $25 \mathrm{~mm} / \mathrm{h}$ and her thorax CT scan shows no evidence of residual disease (figure 3 ).

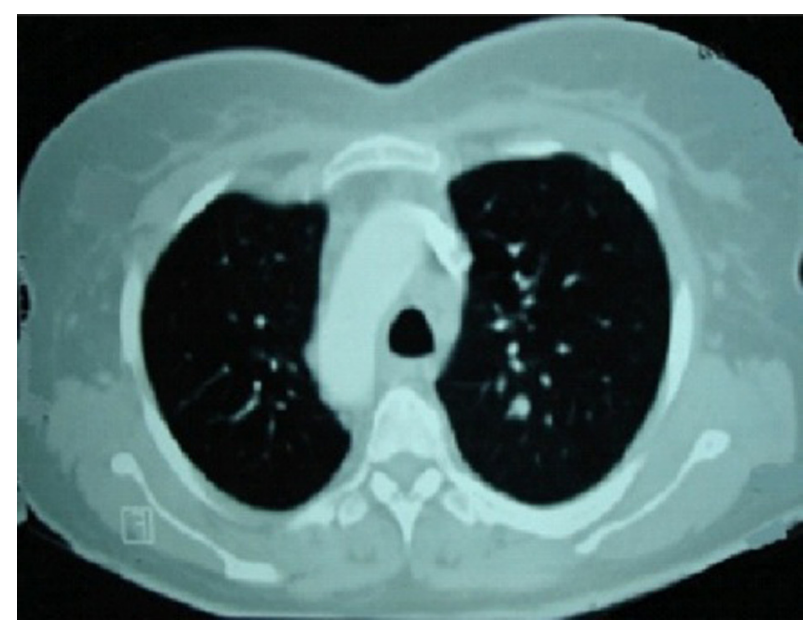

Figure 3 Post-treatment thorax CT scan showing no evidence of residual disease.

\section{DISCUSSION}

Sarcoidosis is a variable multi-system disorder characterised histologically by the presence of non-caseating granulomas in affected tissues. The aetiology of sarcoidosis remains unclear. Sarcoidosis has an uneven distribution, with high prevalence rates in European countries. Pathological diagnosis of sarcoidosis relies heavily on the exclusion of other causes of non-necrotising granulomas. Granuloma formation is a non-specific immunological response which can be triggered by a wide range of infections, chemicals, enzyme defects, neoplasms, allergens and other conditions. ${ }^{2}$ NSG is a rare and still poorly understood variant of sarcoidosis. ${ }^{3}$ A survey of the literature shows that this disorder is uncommon. ${ }^{4-7}$ In 1973, Liebow ${ }^{4}$ made the first reference to a disease characterised by sarcoid-like granulomas with vasculitis and necrosis when describing his classification of pulmonary angitis and granulomatosis not caused by known infectious agents or associated with rheumatoid disease. He called this disease 'necrotising sarcoid granulomatosis' and initiated the debate as to whether the disease represented necrotising angitis with a sarcoid reaction or sarcoidosis with necrosis of the granulomas and vessels. NSG is diagnosed on the basis of pathological features and shares common histological and clinical patterns with sarcoidosis. Clinical features include a subacute onset of fever, night sweats, cough, pleuretic chest pain, dyspnoea and malaise. The disease usually occurs in the fourth to sixth decades of life and mostly affects women. As previously noted, most patients experience pulmonary symptoms with a small percentage of cases being described with extra-pulmonary involvement, which most commonly affects the eyes and central nervous system. ${ }^{1}$ Our patent was a 58-year-old Iranian woman with a non-productive cough, night sweats, low-grade fever and weight loss. In addition, she had hepatosplenomegaly and abnormal liver function tests. Multiple pulmonary nodules, with or without hilar node enlargement, are a prominent radiographical feature in NSG. In the present case, chest radiography and thorax CT scan showed diffuse bilateral pulmonary nodules, especially around bronchovascular bundles, and small mediastinal lymphadenopathies. Limited 
information is available in the literature about laboratory tests in NSG patients. It was noted that inflammatory markers were elevated in our patient. Interestingly, ACE concentration was normal in the present case, whereas it is elevated in nearly $60 \%$ of patients with active sarcoidosis. $^{8} 9$ Another biological parameter that could be useful for differential diagnosis is ANCA, which was negative in our case. In the present case, the initial diagnosis was tuberculosis based on the patient's ethnic background and the histopathological findings of epithelioid granulomatous tissue with extensive necrosis suggesting tuberculosis. Lack of response to a regimen of anti-tuberculosis drugs let us to reconsider the initial diagnosis and infection by mycobacteria was ruled out. The possibility of therapy resistant Mycobacterium tuberculosis or atypical mycobacteria was rejected because of the negative BAL culture and the absence of mycobacteria in endobronchial biopsy specimens, and the diagnosis was changed to sarcoidosis with extensive necrosis. Data on the nature of NSG and its relationship to sarcoidosis are controversial. Clinical (frequency and severity of systemic symptoms), biological (normal ACE level) and specific histopathological data indicate that NSG is intermediate between sarcoidosis and systemic necrotising vasculitides. The prognosis of NSG is favourable, as shown in our patient who was treated with prednisone and made a remarkable recovery. In conclusion, NSG is a rare and probably distinct entity with clinical, radiological and histopathological symptoms that mimic tuberculosis. ${ }^{7}$ A diagnosis of NSG should be considered in patients with necrotising granulomatous inflammation when bacteriological proof of tuberculosis is lacking. In addition, in contrast to many previous reports, extra-pulmonary manifestations can be found in NSG.

\section{Learning points}

NSG is a rare and probably distinct entity with clinical, radiological and histopathological symptoms that mimic tuberculosis.

- A diagnosis of NSG should be considered in patients with necrotising granulomatous inflammation when bacteriological proof of tuberculosis is lacking.

- In addition, in contrast to many previous reports, extrapulmonary manifestations can be found in NSG.

Acknowledgements The authors thank Mr Atashi for his valuable assistance. Competing interests None.

Patient consent Obtained.

\section{REFERENCES}

1. Hammersley JR, Goyal R, Taji J. Atypical presentation of sarcoid: necrotizing sarcoid granulomatosis. Chest 2009.

2. Huaringa AJ, Zetola NM, Leyva F, et al. Necrotizing granulomatosis causing a malignant airway obstruction. Internet J Pulm Med 2000:1.

3. Beckers EAM, Sie TB. Necrotizing sarcoid granulomatosis mimicking tuberculosis: a case report. Eur J Intern Med. 1999:10:171-4.

4. Liebow AA. The J. Burns Amberson lecture-pulmonary angiitis and granulomatosis. Am Rev Respir Dis 1973;108:1-18.

5. Churg A. Pulmonary angiitis and granulomatosis revisited. Hum Pathol 1983;14:868-83.

6. SsIdana MJ. Necrotizing sarcoid granulomatosis: clinico-pathologic observation in 24 patients. Lab invest 1978;38:364.

7. LeGall F, Loeuillet L, Delaval $P$, et al. Necrotizing sarcoid granulomatosis with and Without extrapulmonary involvement. Pathol Res Pract 1996;192:306-13.

8. Lieberman J, Nosal A, Schlessner A, et al. Serum angiotensin-converting enzyme for diagnosis and therapeutic evaluation of sarcoidosis. Am Rev Respir Dis 1979;120:329-35.

9. Rohatgi PK. Serum angiotensin converting enzyme in pulmonary disease. Lung 1982;160:287-301.

This pdf has been created automatically from the final edited text and images.

Copyright 2012 BMJ Publishing Group. All rights reserved. For permission to reuse any of this content visit

http://group.bmj.com/group/rights-licensing/permissions.

BMJ Case Report Fellows may re-use this article for personal use and teaching without any further permission.

Please cite this article as follows (you will need to access the article online to obtain the date of publication).

Binesh F, Halvani H, Navabii H. Systemic sarcoidosis with caseating granuloma. BMJ Case Reports 2012;10.1136/bcr.05.2011.4278, Published XXX

Become a Fellow of BMJ Case Reports today and you can:

- Submit as many cases as you like

- Enjoy fast sympathetic peer review and rapid publication of accepted articles

- Access all the published articles

- Re-use any of the published material for personal use and teaching without further permission

For information on Institutional Fellowships contact consortiasales@bmjgroup.com

Visit casereports.bmj.com for more articles like this and to become a Fellow 